\title{
“Comendo pelas beiradas": vigilância epistemológica e a abordagem Bourdieusiana no campo contábil
}

\author{
MARA VOGT ${ }^{1}$ \\ MARCIA ZANIEVICZ DA SILVA ${ }^{1}$ \\ IONE RIBEIRO VALLE ${ }^{2}$ \\ ${ }^{1}$ Universidade Regional de Blumenau (Furb) / Programa de Pós-Graduação em Ciências Contábeis, Blumenau - SC, Brasil \\ ${ }^{2}$ Universidade Federal de Santa Catarina (UFSC) / Programa de Pós-Graduação em Educação, Florianópolis - SC, BRASIL
}

\begin{abstract}
Resumo
Têm aumentado os estudos com temáticas totalmente diferenciadas na área contábil, alguns mais extravagantes e outros mais inofensivos. Contudo, em ambos os casos, é necessário dar atenção e domínio ao assunto para produzir novos conhecimentos com clareza e coerência. É isso que o sociólogo francês Pierre Bourdieu denomina, em linhas gerais, de vigilância epistemológica. Notadamente a teoria de Bourdieu, em especial a do campo, capital e habitus, tem sido utilizada nas mais diversas áreas do conhecimento e, nos últimos anos, com alguma preeminência na área contábil, mesmo que de modo secundário, como complemento conceitual. Por meio da vigilância epistemológica, recomendada por Bourdieu, este ensaio teórico teve por objetivo analisar a coerência na utilização da abordagem bourdieusiana no campo contábil, bem como indicar novas possibilidades de estudos, tendo como ponto de partida algumas pesquisas já realizadas. Com base na obra desse autor e de alguns de seus seguidores, foi possível observar falta de coerência em algumas pesquisas, ou seja, aquilo que Bourdieu (2001) nominou de allodoxia.
\end{abstract}

Palavras-chave: Contabilidade. Bourdieu. Vigilância Epistemológica. Axiologia. Allodoxia.

\section{Epistemological surveillance and the Bourdieusian approach in the accounting field}

\begin{abstract}
A variety of themes have increasingly been studied in accounting; some of them are quite extravagant, others less. In any case, it is necessary to dedicate attention and develop expertise on these themes to produce new knowledge with clarity and coherence. This is what French sociologist Pierre Bourdieu calls, in general, epistemological surveillance. Notably, Bourdieu's theory, especially that of the field, capital, and habitus, has been used in the most diverse areas of knowledge and, in recent years, with some prominence in the accounting area, even if in a secondary way, as a conceptual complement. This theoretical essay analyzes the coherence in using the Bourdieusian approach in the accounting field through epistemological surveillance. It also recommends new possibilities for studies based on previous literature. The analysis of the work of this author and some of his followers demonstrates that some studies lack coherence, a phenomenon Bourdieu (2001) calls allodoxia.
\end{abstract}

Keywords: Accounting. Bourdieu. Epistemological Surveillance. Axiology. Allodoxia.

\section{“Comiendo por los bordes": vigilancia epistemológica y enfoque Bourdieusiano en el campo contable}

\section{Resumen}

Los estudios con temas totalmente diferentes en el área de contabilidad han aumentado, algunos más extravagantes y otros más inofensivos. Sin embargo, en ambos casos, es necesario darle atención y dominio al tema para producir nuevos conocimientos con claridad y coherencia. Esto es lo que el sociólogo francés Pierre Bourdieu llama, en general, vigilancia epistemológica. Cabe destacar que la teoría de Bourdieu, especialmente la del campo, el capital y el habitus, se ha utilizado en las más diversas áreas del conocimiento y, en los últimos años, con cierta prominencia en el área contable, aunque sea de manera secundaria, como un complemento conceptual. A través de la vigilancia epistemológica, recomendada por Bourdieu, este ensayo teórico tuvo como objetivo analizar la coherencia en el uso del enfoque bourdieusiano en el campo de la contabilidad, así como indicar nuevas posibilidades de estudios, tomando como punto de partida algunas investigaciones ya realizadas. Con base en el trabajo de este autor y algunos de sus seguidores, fue posible observar una falta de coherencia en algunos estudios, es decir, lo que Bourdieu (2001) denominó allodoxia

Palabras clave: Contabilidad. Bourdieu. Vigilancia epistemológica. Axiología. Allodoxia. 


\section{INTRODUÇÃO}

Pierre Félix Bourdieu foi um sociólogo reconhecido por suas discussões relevantes para a Ciência Social, as quais envolvem aspectos como as relações de poder e a tríade que auxilia a explicação dessas relações: campo, habitus e capitais. Além disso, foi um pesquisador que defendeu a axiologia do saber, ou seja, tudo aquilo que se refere a um conceito de valor e que merece investigação em diversos contextos (Bourdieu, Chamboredon \& Passeron, 2015) e em diversas áreas, por exemplo: Educação, Economia, Administração, História, Design, Marketing, Moda, Direito e Contabilidade.

Como pesquisador, além da axiologia do saber, Bourdieu enfatizava a importância da vigilância epistemológica, que diz respeito ao fato de os dados, as análises, as escolhas e a teoria serem "vigiados" em relação à sua coerência com a proposta do estudo (Bourdieu et al., 2015). Os autores deixam claro que, caso não haja coerência na utilização dos conceitos (axiologia), teremos a allodoxia: doxas (verdades) enviesadas, ou seja, verdades apropriadas de forma equivocada (Bourdieu et al., 2015). Essa allodoxia é produzida, por exemplo, pela distância que separa os campos intelectuais em todo o mundo, sendo necessário, em âmbito global, reconhecer as diferenças de um contexto para o outro (Bourdieu, 1997b). Assim, percebemos a importância que Bourdieu atribui à coerência na utilização dos conceitos e teorias, independentemente do pesquisador, objeto ou da área estudados.

Diante do exposto e considerando a relevância da obra sociológica de Bourdieu, este ensaio teórico tem por objetivo analisar a coerência na utilização da abordagem bourdieusiana no campo contábil, bem como indicar novas possibilidades de estudos, indo além do já explorado na área.

Ao longo da obra de Bourdieu, o autor explicita a necessidade da vigilância epistemológica, como já afirmamos. Bourdieu (2001) evidencia que a pesquisa é um discurso ao qual o agente se expõe e pelo qual corre riscos. Além do mais, o autor frisa que por vezes os pesquisadores ignoram fundamentos metodológicos importantes. Contudo, para Bourdieu (2001), a pesquisa é algo que merece seriedade (rigor), difícil de ser embasada em apenas uma metodologia, uma vez que existem várias que podem ser utilizadas, sendo necessário levar o contexto em consideração para cada situação.

Antes de expor como os estudos na área contábil se apropriaram da teoria de Bourdieu, é importante atentar para o entendimento do que é poder para esse autor e de onde emergiu, em sua obra, esse conceito. $O$ conceito de poder é complexo e, de acordo com Bourdieu (1989), está diretamente relacionado à dominação e à reprodução do status quo. Hey (2017, p. 293) observa que, para ser eficaz, o poder deve ter e se apresentar na "[...] forma de desconhecimento e de reconhecimento, de enraizamento no corpo de estruturas de dominação, social e historicamente forjadas, atuantes para gerarem uma ordem social. Tal ordem se inscreve nas relações de força, sendo tomada como ordem natural das coisas".

Para Bourdieu $(1989,1991)$, as relações de poder tendem a se reproduzir na forma de poder simbólico, isto é, de poder invisível que só pode ser exercido com cumplicidade dos dominados em relação aos dominantes. Contudo, as relações de poder não devem ser vistas, exclusivamente, como algo negativo e que reprime. Para Bourdieu, as relações de poder são articuladoras, capacitadoras e inventivas. Nesse contexto, é possível formular dois questionamentos. Por que estudar Bourdieu na contabilidade? Como a teoria de Bourdieu contribui para a pesquisa contábil? Levando em consideração a amplitude dessa teoria e sua relevância, Bryer (2011) salienta que é possível compreender a importância de olhar para os estudos desenvolvidos na área contábil, pois a contabilidade é essencial a todas as organizações. Também é relevante destacar que, pautado na abordagem bourdieusiana, a contabilidade reforça as relações de poder estabelecidas no campo, principalmente por permitir que os agentes articulem determinadas questões, necessidades e anseios pessoais (Bryer, 2011).

Ao aplicar os conceitos de Bourdieu para explicar a ausência de estudos com abordagens interpretativas e críticas na contabilidade, Homero (2017) concluiu que a pesquisa contábil brasileira, caracteristicamente positivista e de pouca diversidade, é pouco desenvolvida naquelas abordagens; em parte, pela baixa autonomia do campo acadêmico em relação ao campo profissional. O autor alerta sobre a necessidade de ampliar a variedade temática, metodológica e epistemológica da pesquisa contábil, bem como a aproximação entre a teoria e a prática contábil.

Diante do contexto supracitado e levando em consideração a vigilância epistemológica, analisar a coerência de utilização de conceitos e autores é fundamental quando se trata de pesquisa científica. Isto posto, com base em uma revisão da literatura no contexto brasileiro, constata-se que são escassos os estudos da área contábil que adotam a teoria de Bourdieu como base. 
O que constitui uma lacuna a ser explorada e, com isso, uma contribuição, especialmente com o propósito de oferecer uma reflexão sobre a axiologia do saber de Bourdieu.

A metodologia utilizada foi de natureza exploratória e analítico-descritiva. Foram analisados dados obtidos em exames bibliográficos de forma qualitativa. Para Hoskin e Macve (2000) necessitamos voltar ao passado para descobrir e analisar novas evidências e padrões. No caso deste estudo, volta-se ao passado na busca por estudos anteriores, a fim de identificar o que já foi realizado e, assim, evoluir com os estudos futuros. Ao mesmo tempo, identificar os pontos fortes e fracos dos estudos já realizados com base na coerência, analisando-os por meio da vigilância epistemológica.

Para tanto, na pesquisa são descritos estudos publicados no Brasil, que se apoiam em Bourdieu para esclarecer ou explicar questões relacionadas às temáticas da área de contabilidade. Para a seleção dos estudos, realizou-se uma busca no Portal da Capes (em julho de 2018) com a utilização do termo "Bourdieu", intercalando-o com as demais palavras-chave: "contabilidade", "contábeis", "contábil". Com o filtro de busca estabelecido, foram recuperados, inicialmente, 126 artigos. Excluindo-se as duplicidades e falsas recuperações, obteve-se um corpo de 82 artigos, nos quais, após a leitura do título e resumo, foram identificados aspectos que dizem respeito à abordagem bourdieusiana, especialmente em relação à sua tríade, que envolve o campo, habitus e capital, daí resultando um total de 10 estudos cujas propostas demonstraram-se coerentes com o objetivo desta pesquisa.

Os ensaios teóricos possibilitam ampliar a interdisciplinaridade, promovendo a construção e evolução do conhecimento, sem que haja um padrão ou modelo, demandando mais esforços por parte dos pesquisadores para atingir o objetivo proposto (Meneghetti, 2011). Por meio desses estudos é possível identificar novos elementos, contudo, exige maior reflexão para pensar e repensar fenômenos (Meneghetti, 2011).

Este estudo está organizado em quatro sessões, além da introdução, temos a segunda sessão dedicada à descrição de alguns dos conceitos presentes na obra de Bourdieu. Na sequência, são apresentados os estudos recuperados na área contábil que utilizam os estudos do autor, o que permitiu compor uma nuvem de palavras, gerada com as palavras mais frequentes nos resumos e palavras-chave dos artigos analisados, para, finalmente, apresentar reflexões acerca dessa utilização da obra de Bourdieu na pesquisa contábil.

\section{A TRÍADE CONCEITUAL DE BOURDIEU}

Bourdieu desenvolveu, ao longo dos anos, diversos conceitos para explicar o comportamento das pessoas tendo como referência suas relações. Para isso, propôs uma tríade formada pelo campo, habitus e capital. Para o autor, no campo acontece a construção do objeto que vai comandar ou orientar as práticas da pesquisa. Esse campo é o espaço de pressões, concorrência e disputas entre agentes (Bourdieu, 2005). É relevante destacar que as disputas dentre e entre campos ocorrem com o intuito de conquistar ou redefinir algum ou alguns capitais, podendo abranger o capital econômico, escolar, cultural, social, político, simbólico, dentre outros (Lahire, 2017). Desse modo, inicialmente deve-se compreender o campo, para então entender como se dá o poder neste contexto e como o habitus influencia tais relações, até porque as relações de poder permeiam as relações humanas (Bourdieu, 1989, 1991).

O habitus, para Bourdieu (1989), compreende as experiências anteriores que o indivíduo carrega consigo, o sistema de disposições, as regras, as crenças e as histórias que o influenciam a buscar a legitimação de capital(is), de acordo com os anseios, objetivos, exigências e/ou pressões sofridas por cada um. Para Setton (2002), o habitus é um sistema engendrado no passado e orientado para ações no presente, que podem ser conscientes ou, na maioria das vezes, inconscientes. Contudo, esse habitus não pode ser considerado imutável, pois o sistema de disposições vai sendo 'alimentado' continuamente, estando aberto a novas experiências.

Para completar a tríade, temos o conceito de capital. A teoria proposta por Bourdieu tem como pressuposto que em um campo há sempre algo em jogo e, nesse jogo, há a busca para a obtenção ou fortalecimento de algum(ns) capital(is), o que facilita a conquista de determinadas posições de poder e prestígio. Segundo Bourdieu (1989), o capital é um recurso que possibilita a conquista do poder, ademais, a quantidade de capital que um agente possui é determinante para sua posição no campo, que pode ser de maior ou menor prestígio. Ele esclarece, ainda, que quem tem capital(is) consegue dominar e reproduzir o poder. 
Segundo Bourdieu e Wacquant (1992), um capital só existe e se fortalece se houver um campo, uma vez que o(s) capital(is) confere $(\mathrm{m})$ um poder no interior do campo. Munro (1993) salienta que as posições dos atores sociais no campo são determinadas por volume e composição do capital que possuem, e as lutas em um campo ocorrem para acumular várias formas de capital. Para Baxter e Chua (2008), as diferentes posições em um campo são estabelecidas de acordo com o acesso às formas de capital(is) e à legitimação deste(s).

Em relação aos capitais, tem-se o capital econômico, escolar, cultural, social, político e simbólico, entre outros que são considerados formas de poder (Bourdieu, 1989). Como capital econômico, Bourdieu (1991) considera a riqueza material, sob a forma de remuneração. Lebaron (2017) complementa que pode ser também patrimonial, como: bens imobiliários, automóveis, entre outros. O capital escolar refere-se a conhecimentos, habilidades, qualificações educacionais ou técnicas (Bourdieu, 1998), diplomas, escrita e leitura (Nogueira, 2017), entre outros. Já o capital cultural é composto pela religião, arte, ciência, filosofia, viagens, dentre outras formas (Bourdieu, 2004b; Lebaron, 2017). Por sua vez, o capital social diz respeito a uma rede durável de relações pessoais, estando diretamente relacionado às demais formas de capital (Bourdieu, 1998). O capital político é obtido em forma de votos e refletido na representatividade, bem como por meio de cargos, o que remonta a confiança e obediência (Bourdieu, 1991).

O capital simbólico - muito presente no contexto contábil - é considerado o valor atribuído a um indivíduo pela sociedade, que o reconhece e o valoriza (Lebaron, 2017). Para Bourdieu (1991), este é um capital que advém do prestígio e reconhecimento, da honra e reputação, sendo representado, conforme Bourdieu (1998), por meio de homenagens. O capital simbólico é resultante do acúmulo e combinação dos demais capitais em um dado campo (Bourdieu, 1998).

Lebaron (2017, p. 103, grifo nosso) enfatiza que os capitais sustentados por Bourdieu "[...] podem ser acumulados, convertidos uns nos outros, transmitidos de geração em geração, mas sempre dependentes dos contextos sociais que condicionam seu 'valor' social" e correspondem a um poder simbólico. Isso porque é possível visualizar o poder por toda a parte, mesmo que não seja totalmente visível e, por isso, considerado, muitas vezes, como um poder invisível (Bourdieu, 1989, 1991).

Com base em Bourdieu (1997a), as escolhas sociais nunca são neutras, estão sempre inscritas num jogo de dominação. Diante disso, entende-se, com base no exposto por Munro (1993) e Cooper e Hopper (2006), que o poder na contabilidade é usado para legitimar processos, de modo que os interesses dos atores que utilizam a contabilidade não são neutros. Desse modo, é propício utilizar a teoria das relações de poder propostas por Bourdieu para explicar acontecimentos na área contábil. Além do exposto, Whittle e Mueller (2010) aduzem que a contabilidade pode desempenhar um papel fundamental nas disputas pelo poder, principalmente ao apresentar números que representam uma verdade socialmente aceita sobre o valor das atividades.

Assim, a contabilidade é uma ferramenta para racionalizar o irracional e reforçar as relações de poder (Bryer, 2011). Kuruppu et al. (2016) consideram que o poder e a dominação são inerentes ao social e que é comum os agentes envolvidos na construção de estratégias em determinado campo se esforçarem para dominar, mesmo tendo que contrariar os demais envolvidos. Desse modo, pode-se perceber a contabilidade como útil para promover apostas e estratégias, buscando, ao mesmo tempo, silenciar outras, produzindo uma violência simbólica (Farjaudon \& Morales, 2013). Essa violência simbólica é, para Bourdieu (2001), caracterizada por atitudes como: ironia, grosseria, inibição da fala, duvidar da capacidade alheia, apropriação de ideias sem dar crédito, dentre outras, as quais, conforme Valle (2008), conferem um poder hipnótico às ameaças, broncas, manifestações, ordens ou até mesmo, chamadas à ordem.

Resumidamente e, para melhor elucidar os conceitos, se a tríade de Bourdieu fosse aplicada nesta pesquisa, o campo corresponderia às pesquisas brasileiras na área contábil cuja base teórica se apoia em Bourdieu, o habitus diz respeito às experiências, regras, saberes práticos dos autores (Bourdieu, 1989, 1997a, 2004a) na área contábil e sobre a teoria de Bourdieu. Quanto ao capital, alguns dos capitais relacionados ao campo poderiam ser o escolar, social, econômico e simbólico (Bourdieu, 1991; Lebaron, 2017; Nogueira, 2017). Diante desse tema tão complexo, bem como de conceitos e terminologias diferentes daqueles a que se está acostumado na contabilidade, entende-se o quão importante é o cuidado que se deve ter ao usá-los nas pesquisas, para que não se distorça o que o outro autor quis transmitir. 


\section{A VIGILÂNCIA EPISTEMOLÓGICA}

Ao analisar as pesquisas nacionais que utilizaram Bourdieu na área contábil, nota-se que os estudos desenvolvidos até o momento foram realizados com diferentes perspectivas. Dentre o conjunto de artigos recuperados, o mais antigo é o de Riccio, Mendonça e Sakata (2007). Nele os autores utilizam o modelo conceitual de Pierre Bourdieu sobre campos do conhecimento para analisar a natureza da inserção de Foucault no pensamento contábil, por meio do levantamento e da sistematização de artigos publicados em revistas científicas internacionais de contabilidade. No estudo, os campos do conhecimento equivalem ao campo científico de Bourdieu. Os autores explicitam que o campo do conhecimento contábil, caracterizado como um espaço de dominação e conflitos, é um local no qual os agentes buscam prestígio e reconhecimento.

O estudo de Riccio et al. (2007), embora apresente a relação do campo científico com a busca de prestígio e reconhecimento, oferece pouca discussão sobre o primeiro e deixa de destacar os aspectos do capital simbólico, o qual o agente possui ou busca acumular com o passar do tempo. Riccio et al. (2007) apresentam o capital cultural e simbólico, mas os relacionando com o campo. Deve-se considerar sempre que há leitores que não conhecem determinado autor e obra aos quais o pesquisador se refere em sua pesquisa, o que dificulta, em alguns casos, o entendimento, sendo necessário, portanto, um maior detalhamento de algumas questões, mesmo que, para o pesquisador, elas pareçam lógicas e simples. Um exemplo disso é quando Riccio et al. (2007) tratam de "símbolos" de Bourdieu: o ideal seria que houvesse uma explicação sobre o que são esses símbolos e sua relação com o trabalho.

Nesse caso, poderia ser realizado um estudo analisando como os pesquisadores da área contábil percebem o campo científico, levando em consideração reconhecimento, prestígio, honra (definições que correspondem ao capital simbólico). Outra possibilidade seria pesquisar qual(is) são os capitais que satisfaz(em) os pesquisadores da área contábil e os fazem seguir atuantes. Também se poderia analisar como se dá a 'corrida' pelo melhor CV Lattes entre os pesquisadores da área contábil, considerando neste caso o campo científico e o capital social, escolar e simbólico.

Outros estudos também voltaram-se para o campo científico na área contábil, a saber: Araújo, Brito, Ribeiro e Lopes (2016) e Homero (2017). Araújo et al. (2016) objetivaram compreender a forma como a academia científica entende e utiliza o relatório de administração; desse modo, tratam do campo científico e empresarial. Já no início do referencial teórico, os autores deixam claro que abordam o campo como um conjunto formado por redes de relacionamento usualmente integradas e entrelaçadas e não como uma arena de poder e conflito, conforme Bourdieu. Além disso, Araújo et al. (2016) enfatizam que Bourdieu não foi o referencial de sustentação do trabalho; consideram mais significativos os estudos de DiMaggio e Powell (1991, 2004) e as interpretações de Machado-da-Silva, Guarido e Rossoni (2010). A ênfase, por parte de Araújo et al. (2016), sobre a escolha dos autores para a sustentação do trabalho é interessante e positiva por dois aspectos: i) demonstra que têm um entendimento sobre o conceito de campo, o estudaram e escolheram aquele o conceito e autor(es) que consideram mais adequados para o contexto analisado; ii) posicionam-se e expõem claramente as escolhas teóricas que guiam o estudo. Contudo, como sugestão para estudos futuros, poderia ser realizado um estudo similar, porém analisando, por meio de análise de discurso, o poder simbólico por trás da elaboração dos relatórios de administração e, até mesmo, dos relatórios de sustentabilidade e relatórios anuais.

Ao observar a constituição do campo científico e a baixa diversidade da pesquisa contábil brasileira para explicar a ausência de uma linha consolidada de pesquisas interpretativas e críticas em contabilidade no Brasil, Homero (2017) destaca que a pouca diversidade observada na pesquisa contábil brasileira é consequência da baixa autonomia do campo científico em relação ao campo profissional. Além disso, argumenta que as posições de destaque no meio acadêmico, ao longo dos anos, foram ocupadas por indivíduos com atuação também no campo profissional. Outro ponto verificado pelo autor para a falta de autonomia foi a prevalência dos estudos na área contábil com abordagem positivista e, consequentemente, o poder exercido pelos corpos editoriais dos periódicos de maior destaque. O autor alerta para a necessidade de ampliação da variedade temática, metodológica e epistemológica e, ainda, para a aproximação entre a academia e a prática contábil.

Diante das preocupações e inquietações expostas no artigo de Homero (2017) sobre o campo científico na contabilidade, é possível utilizar-se da obra Os Usos Sociais da Ciência, de Bourdieu (2004b), em busca de explicações para essa situação, tendo em vista que o campo científico é distinto dos demais, o que proporciona, segundo o autor, mais fracassos que sucessos e por consequência exige muita criatividade, inovação e vontade. De acordo com Bourdieu (1989), é preciso romper com a passividade empirista e ratificar as pré-construções do senso comum, fazendo a diferença no mundo acadêmico e, 
com isso, possibilitando a evolução do conhecimento científico. Se isso realmente acontecer, haverá ou será possível dar início a uma verdadeira revolução científica em todos os campos, inclusive na contabilidade. Por conseguinte, mais pesquisas e pesquisadores seriam reconhecidos.

Além disso, complementando e buscando encontrar respostas à preocupação de Homero (2017) com o campo científico na contabilidade, busca-se aqui novamente respaldo em Bourdieu (1989), isto é, em sua elucidação de que a imigração de ideias raramente se faz sem dano, uma vez que são definidas consciente ou inconscientemente. Nesse caso, entende-se que todo o esforço sempre é e será válido, por mais que não seja reconhecido da forma como deveria ser. Para tanto, podemos entender que, segundo Bourdieu (2004b), o campo científico é amplo, nele há pesquisadores que, ao desenvolver suas pesquisas, deparam-se com diversos empecilhos, sejam advindos da própria instituição na qual estão inseridos, de poderes políticos presentes neste ambiente, ou mesmo devido à posição que ocupam neste campo, bem como à concorrência acirrada. Além disso, agentes ocupam posições que demonstram autonomia. Compreende-se que seria interessante uma maior demanda para o novo, para pesquisas inovadoras e diferenciadas na área contábil.

Malsch, Gendron e Grazzini (2011) salientam que não se aventurar investigando problemas diferentes do tradicional e do comum pode restringir o desenvolvimento de ideias inovadoras. Diante do exposto, pesquisas futuras poderiam retomar o estudo de Homero (2017) e avançar no que diz respeito ao campo científico relacionado ao capital social, analisando como as relações sociais, estabelecidas por meio das coautorias com pesquisadores de outras universidades brasileiras e até mesmo de outros países, acontecem na área contábil e se são convertidas em capitais simbólicos, por exemplo: a publicação em top journals.

Nessa mesma perspectiva, Frezatti, Nascimento e Junqueira (2009) discutem a escassez de veículos nacionais e internacionais reconhecidos para publicação na área de Contabilidade Gerencial. Os autores frisam que, embora existam publicações nessa área em periódicos norte-americanos, a participação é pequena em comparação com outras áreas da contabilidade e ainda menor quando se trata de autores que não são norte-americanos. Para explicar esse fato, recorrem a uma citação de Bourdieu (1992), na qual descreve que os mecanismos de reprodução social visam à legitimação daquilo que é considerado como 'o correto'. Na direção da pesquisa de Frezatti et al. (2009), novos estudos poderiam avançar explorando a questão do habitus, ou seja, dos saberes práticos e experiências anteriores que estão atrelados a este contexto e que dificultam a inserção de novos estudos e de diferentes autores da área. Além disso, a questão do capital científico pode ser uma abordagem útil para explicar as publicações de determinada 'elite'.

No estudo sobre consultoria internacional em expansão e formas emergentes de globalização das trocas e contenciosos gerenciais, Donadone (2010) salienta que o formato dos embates entre consultores e gerentes é direcionado pelo posicionamento dos agentes nos respectivos campos, havendo mitigação na diferenciação entre consultores e gerentes em posições homólogas. Os embates se naturalizam com a posição dominante, na qual gerentes atribuem à atuação dos consultores o modelo de conduta a ser seguido, o que pode ser considerado um processo de violência simbólica, no contexto desse conceito preconizado por Bourdieu (2000).

Com base no exposto, o estudo de Donadone (2010) poderia ter oferecido uma discussão mais detalhada sobre a violência simbólica, descrevendo, por exemplo, como ocorre a naturalização da posição dominante. É relevante observar que, segundo Mauger (2017), a naturalização da posição dominante ocorre pela fala, por gestos, coisas e acontecimentos. De todo modo, novos estudos poderiam explorar a violência simbólica no campo científico da contabilidade, sob diversas óticas. Por exemplo, como ocorre a violência simbólica na relação coordenação-professores de pós-graduação, na relação professor-aluno, orientador-orientando e até mesmo na relação entre colegas de turma. Ou em outros campos, como empresas familiares, instituições públicas ou de classe.

Miranda, Casa Nova e Cornacchione (2012) utilizaram duas obras de Bourdieu para sustentar o conceito de referência relativa ao profissional/professor ao avaliar os saberes predominantes dos docentes percebidos como professores-referência no curso de Graduação em Ciências Contábeis de uma universidade pública brasileira. Para os autores, o termo referência diz respeito aos docentes que se destacam positivamente ante os discentes. Como forma de avançar nessa discussão, novas pesquisas podem identificar professores-referência da pós-graduação em Contabilidade, com intuito de questionar a respeito de como se sentem; quais capitais mobilizam; como os agentes que circulam nos campos em comum os percebem; como os habitus e capitais são utilizados nesse contexto.

No contexto empresarial, com intuito de analisar o efeito do capital social do Conselho de Administração (board) no valor de mercado das empresas listadas na BM\&F Bovespa, Aranha, Rossoni e Mendes-da-Silva (2016) adotam como indicador 
do capital social os recursos relacionais presentes nos laços diretos, indiretos e heterogêneos do board. Sendo assim, os autores utilizaram o volume de capital social, mensurado pelo tamanho da rede e do volume de capital (econômico, cultural e simbólico), possuído pelo indivíduo conectado à rede. No entanto, o estudo não descreve exatamente o que são os outros capitais e como foram por eles considerados. Outro ponto relevante é o fato de os autores adotarem como referência a obra mais contemporânea de Lin, Cook e Burt (2001) para conceituar capital social. Bourdieu é apresentado como um autor secundário para apoiar alguns conceitos no referencial teórico. Diante disso, futuros estudos podem ampliar os achados de Aranha et al. (2016) observando o capital social presente no board interlocking, isto é, as redes colaborativas, laços sociais presentes entre conselheiros de administração, pela lente teórica de Bourdieu.

Outros autores que adotaram o conceito de capital foram Mizumoto, Artes, Lazzarini, Hashimoto e Bedê (2010), ao examinar empiricamente o impacto de três fatores que podem prolongar a sobrevivência de empresas nascentes: o capital humano do empreendedor, seu capital social e a adoção de práticas gerenciais após a abertura da nova firma. Destacam que as discussões sobre a importância do capital social tomaram impulso com os esforços de sociólogos como Bourdieu (1986) e Coleman (1988), tendo em vista que estes autores enfatizaram os benefícios que atores podem obter por meio de sua inserção em redes sociais. Novos estudos poderiam utilizar os dois autores clássicos, comparando os resultados empíricos por duas perspectivas, já deixando claro desde o início do trabalho em que o conceito de capital social dos autores se difere. Além disso, pouco se sabe sobre se e como os capitais são mobilizados para prolongar e proteger empresas nos diferentes ciclos de vida: nascimento, crescimento, maturidade, renascimento e declínio.

Barbosa, Higgins, Cunha e Ribeiro (2016), ao analisar as redes de coautoria acadêmica dos programas de ciências contábeis do Brasil, também consideraram o conceito 'capital social' de Bourdieu (1980) e Coleman (1988, 1992, 1994), expondo que esse capital é o principal produto de exportação sociológico nos últimos trinta anos. Os autores complementam que a representação social de Coleman e Bourdieu permaneceu por muitos anos no nível de uma noção ambígua, entre o lugar comum e a analogia. No estudo, os autores oportunamente enfatizam que cada um dos clássicos busca esclarecer problemas diferentes e ambos contribuíram de forma decisiva na difusão científica desse conceito.

Tendo como base o estudo de Barbosa et al. (2016), uma lacuna poderia ser preenchida por meio de estudos futuros, no intuito de analisar empiricamente como os capitais se retroalimentam, considerando que estes são acumulados e podem ser convertidos uns nos outros, contribuindo para a reprodução da dominação social, pois quanto mais capital o agente tiver, mais ele conseguirá dominar pelo poder que possuirá e, consequentemente, reproduzirá esse poder. Além disso, poderiam ser consideradas as demais formas de capital, como o capital econômico, escolar, político, dentre outros que poderão emergir no campo que for investigado.

Por fim, no estudo de Tana, Mesquita, Gonçalves e Martins (2017), o conceito de capital social também é utilizado, contudo, além da abordagem de Bourdieu $(1998,2006)$ e de Coleman $(1988,1994)$, diferencia-se por resgatar os conceitos de capital social expostos por Burt $(1992,2000)$ para avaliar a influência das redes sociais sobre as capacidades gerenciais de cooperativas que atuam no setor lácteo. Na pesquisa, os autores apresentaram um constructo com variáveis que dizem respeito ao relacionamento com as comunidades, envolvendo o reconhecimento dado à cooperativa pelas comunidades afetadas. No contexto observado, concluem que a parceria pode ser considerada como capital social. Devido às diferentes abordagens apresentadas para medir o capital social, Tana et al. (2017) destacaram que a dificuldade de medir os benefícios da rede é também apresentada por Burt, Bourdieu e outros autores.

Para tanto, no contexto de cooperativas, estudos similares ao de Tana et al. (2017) podem avançar levando em consideração o habitus, isto é, as experiências anteriores, saberes, regras e crenças e, além disso, discutir o reconhecimento e os benefícios resultantes desse capital social por meio do capital simbólico. Seria interessante, ainda, comparar os resultados de diferentes tipos de cooperativas (por exemplo: agropecuárias, de produção, de crédito, dentre outras).

Outra questão observada no estudo de Tana et al. (2017) é que, para Bourdieu (2006) ${ }^{1}$, o capital social é uma soma de recursos, reais ou virtuais. Porém, ao consultar a obra de Bourdieu, verifica-se que o autor considera que o capital social se refere à relação com as pessoas, isto é, aos laços sociais e não exatamente como a soma de 'recursos' reais ou virtuais (Bourdieu, 2005).

Diante do exposto e sem a pretensão de abranger a totalidade de possibilidades, é possível perceber quão rica e atual é a obra de Bourdieu e as inúmeras oportunidades para novas pesquisas. No entanto, é primordial o cuidado com o uso das

\footnotetext{
${ }^{1}$ Buscamos a obra de Bourdieu (2006) citada e esta é na realidade de 2005 e não de 2006.
} 
palavras, com seus significados. Trata-se da vigilância que Bourdieu tanto preconiza, especialmente no contexto das pesquisas qualitativas e críticas, pois, neste caso, as palavras possuem maior poder. Ademais, nas palavras de Wacquant e Akçaoğlu (2018, p. 148), "Para apreender o modus operandi mental distintivo de qualquer grande pensador - seja Bourdieu, Hannah Arendt ou IbnKhaldun - você deve se enredar profundamente em sua teia intelectual", e, ainda, "[...] O objetivo não é converter o aluno (a teoria social não é teologia), mas torná-lo familiarizado com um modo particular de pensar, do qual você pode se apropriar e adaptar às próprias necessidades analíticas no futuro". Depreende-se disso que é possível revisitar a obra de Bourdieu para o campo contábil e, em especial o campo contábil brasileiro, no entanto, é necessário vigilância e, principalmente, profunda compreensão sobre os conceitos primários de sua obra, contextualizados em seu tempo, espaço e campo.

\section{“COMENDO PELAS BEIRADAS”}

Com base na análise dos resumos e das palavras-chave dos estudos recuperados no processo de uma busca em periódicos nacionais e considerando apenas aqueles utilizados para este estudo (os apresentados na seção anterior), os quais apresentavam conceitos e/ou argumentos respaldados na teoria de Bourdieu, foi elaborada uma nuvem de palavras, conforme pode ser visualizado na Figura 1.

Figura 1

Nuvem de palavras

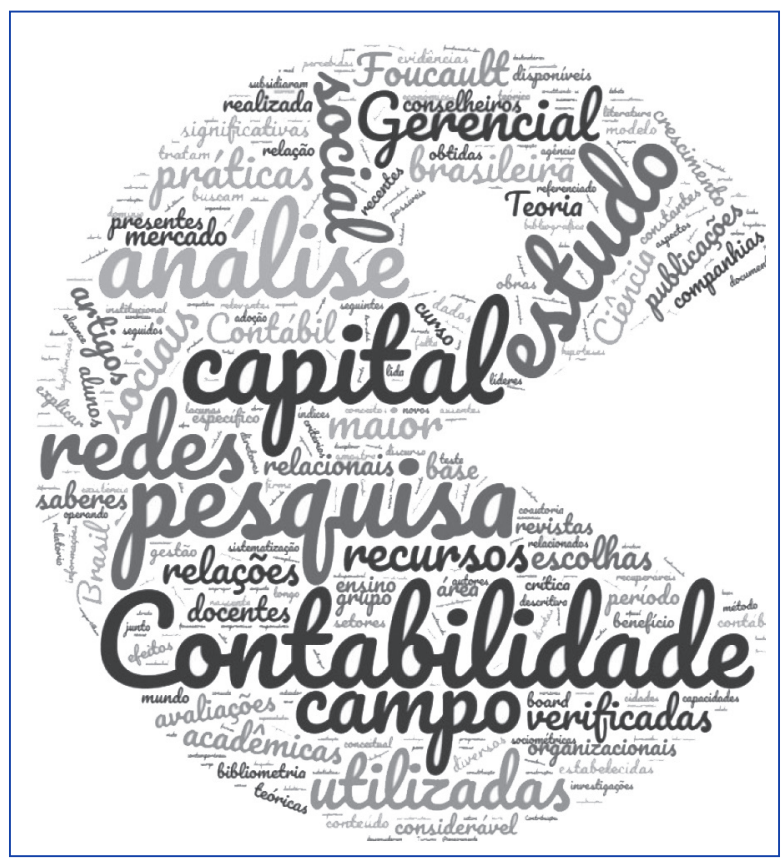

Fonte: Dados da pesquisa.

É possível visualizar o destaque da palavra contabilidade, a qual é pertinente em decorrência da seleção dos artigos. Além disso, as palavras capital, pesquisa, redes, campo, estudo e análise estão em evidência, bem como social e gerencial, e se mostram mais presentes que as demais palavras nos resumos analisados. Diante do exposto, é possível perceber que as temáticas que se sobressaíram estão relacionadas às redes, relações sociais, ou seja, ao capital social. A palavra capital está em evidência, pois os estudos de Frezatti et al. (2009), Mizumoto et al. (2010), Barbosa et al. (2016), Aranha et al. (2016) e Tana et al. (2017) tratam sobre o capital social, e o tema principal sempre esteve relacionado à contabilidade, ou seja, ao campo.

Outra palavra em evidência é campo, uma vez que mais da metade dos estudos analisados neste ensaio investigaram o campo científico: Riccio et al. (2007), Miranda et al. (2012), Araújo et al. (2016) e Homero (2017). Pesquisa e estudos também são palavras em evidência na Figura 1, justamente pela predominância do olhar para o campo científico, o campo dos pesquisadores e outros profissionais que de alguma forma possuem relação direta com esse campo. 
Os estudos analisados da área gerencial que utilizavam algum termo de Bourdieu foram os de Frezatti et al. (2009), Donadone (2010) e Mizumoto et al. (2010). O primeiro discute a questão das redes, ou seja, do capital social. Donadone (2010) analisou a temática da violência simbólica dentro dessa área e, por fim, Mizumoto et al. (2010) também estudaram o capital social com base em Bourdieu e outros autores.

Chama a atenção que, mesmo que o autor Foucault não se destaque na nuvem de palavras, ele está presente. No entanto, observamos que o nome Bourdieu, a qual é o foco deste estudo, também não é facilmente identificada. Isso decorre do fato de a maioria dos resumos não explicitarem o autor. Ao retomar os resumos, foi possível constatar que o estudo de Riccio et al. (2007) utiliza o modelo conceitual de Pierre Bourdieu sobre campos do conhecimento para analisar a natureza da inserção de Foucault no pensamento contábil. Verificou-se que os autores deram ênfase e citaram diversas vezes Foucault em seu resumo, fato que levou o autor a se sobressair na nuvem de palavras.

Desse modo, observou-se que apenas os estudos de Riccio et al. (2007) e Homero (2017) apresentaram o nome de Bourdieu como base da pesquisa em seus resumos, citando-o apenas uma vez e ambos tratando do campo científico. Tal fato talvez decorra do receio dos autores em colocar em evidência um sociólogo pouco difundido no campo da pesquisa contábil. Pode ser oportuno observar que, ao fazer uma busca no Portal Scopus, nas revistas relacionadas à contabilidade, às organizações e aos negócios, é possível recuperar em torno de 50 obras cuja temática bourdieusiana relaciona-se com a contabilidade. A primeira foi em 1995, publicada por Lee e se intitula Shaping the US academic accounting research profession: The american accounting association and the social construction of a professional elite. Daquele ano até 2015, observamos uma publicação pouco expressiva (entre um e quatro artigos por ano, com exceção do ano de 2011), fato que toma outra dimensão a partir de 2016, indicando que Bourdieu 'foi descoberto' pela pesquisa contábil publicada em língua inglesa.

\section{REFLEXÕES CRÍTICAS}

Reconhecer que as pesquisas pautadas na teoria de Bourdieu estão presentes no campo contábil, ainda que isso esteja acontecendo aos poucos, é importante. Admitir que existem limitadores e resistências no campo em relação às pesquisas que se afastam do mainstream é necessário. Porém um ponto relevante é o fato de essas pesquisas estarem consolidando seu espaço e se inserindo em periódicos da área contábil. Constatamos que a obra de Bourdieu está gradativamente se inserindo no campo da pesquisa contábil, o que nos parece ser um processo o qual ainda irá render bons resultados, haja vista as múltiplas possibilidades que a vasta obra desse sociólogo tem para oferecer aos estudos dedicados a observar agentes, capitais, campos, habitus, hexis corporal, violência simbólica.

Entendemos que a maioria dos trabalhos analisados tende a concentrar atenção no estudo sobre o capital social, o que se mostra incipiente em relação à amplitude da teoria, bem como à tríade de Bourdieu das relações de poder - aqui se considera que o desafio é abranger a tríade no restrito espaço dos periódicos. Townley (2014) salienta que, no geral, foram poucos os estudos realizados até então que combinaram a análise da tríade campos, habitus e capital, tendo a maioria usado somente um elemento. O mesmo ocorre na área contábil, na qual a teoria de Bourdieu ainda não foi explorada de forma significativa (Malsch et al., 2011).

Contudo, Townley (2014) considera que os três elementos (campos, habitus e capital) existem de forma teórica para o entendimento das práticas, independentemente da área investigada. Malsch et al. (2011) destacam que, mesmo utilizando somente um dos conceitos de Bourdieu, de forma fragmentada, não se devem menosprezar tais estudos, mas se deve considerar que pode ser difícil ou impossível perceber os benefícios da estrutura de Bourdieu. Diante do exposto, prossegue-se, aqui, com a inquietação de Malsch et al. (2011, p. 194-220): "Faz sentido usar de forma fragmentada certos conceitos extraídos de um sistema abrangente de pensamento?"; "[...] por que Bourdieu raramente é completamente mobilizado na literatura contábil?"

Quando Bourdieu (1989, p. 32) destaca que "[...] para romper com a passividade empirista, que não faz senão ratificar as préconstruções do senso comum" - procedimento sobre o qual ele se manteve vigilante sobre si mesmo em toda a sua obra -, apresentam-se algumas questões para reflexão: por que é tão difícil romper, quebrar paradigmas? Levantar novas questões e propor novos métodos, ideias brilhantes que ninguém antes ousou expor? Será que não estamos sendo apenas meros expectadores, produzindo mais do mesmo? Por mais que seja difícil, quem sabe esse seja o exercício necessário, capaz de fazer a diferença na academia, possibilitando a evolução do conhecimento científico? 
A partir do momento em que os pesquisadores ousarem sair da 'zona de conforto' e pensar 'fora da caixinha', Bourdieu (1989) salienta que haverá uma mudança, seja esta significativa ou não, mas será um caminho sem volta. Assim, é preciso saber olhar, concordar, discordar e criticar quando for necessário, pois discordar e criticar são importantes para que haja evolução.

Em todos os casos, ao analisar a evolução da pesquisa contábil baseada na abordagem bourdieusiana, percebe-se e acredita-se que, aos poucos e ao longo dos anos, ela está se consolidando e sendo aprofundada. Novos pesquisadores contribuem com os atuais na busca por seu espaço. Vale ressaltar que a escolha da expressão popular 'comendo pelas beiradas' intenciona retratar a realidade das pesquisas da área contábil que utilizam Bourdieu, uma vez que vêm sendo inseridas aos poucos em eventos e periódicos da área sem que chamem muito a atenção, até que isso se torne algo amplamente aceito pelos 'pares'.

"Comendo pelas beiradas" refere-se também ao sentido da relação com os elementos que estão sendo analisados, sendo estes na maioria dos estudos os mesmos, ou seja, basicamente o campo científico e o capital social, embora se tenham observado alguns estudos voltados à área gerencial - entre os quais um destes levou em consideração a noção de violência simbólica. Outro ponto de destaque é o uso, por alguns estudos, da teoria de Bourdieu para explicar o capital social, conjuntamente com autores como Lin, Burt e Coleman. Isso pode ser enriquecedor, desde que haja a vigilância epistemológica e a apropriação adequada de conhecimentos sobre como os conceitos de capital social, presentes na obra de diferentes autores, estão imbricados e em quais aspectos se contrapõem. É preciso salientar que, embora algumas pesquisas façam menção a capital econômico, capital simbólico, capital cultural e habitus, as discussões ainda permanecem retraídas quando o conjunto de obras proposto por Bourdieu oferece inúmeras possibilidades.

Diante do exposto, se tantos fatos podem ser observados pela lente teórica de Bourdieu na área contábil, pergunta-se: por que ainda há tanta resistência à aceitação? Será que essa resistência é reflexo da pouca atenção dos programas de pós-graduação à sociologia? Seria interessante haver uma reflexão a esse respeito, para que houvesse mais interdisciplinaridade. O fato de teorias de outras áreas não serem exploradas pode ser explicado, pelo menos em parte, pela preocupação quanto à aceitação das pesquisas. Além do mais, no caso de Bourdieu, mesmo que seja um autor renomado no contexto multidisciplinar e internacional, em especial na educação, é preciso ter cuidado ao utilizar sua teoria para embasar e sustentar determinadas questões, pois corre-se o risco de forçar explicações que não são possíveis.

É preciso retomar e lembrar que deve-se levar sempre em consideração a allodoxia, em virtude de alguns conceitos dependerem da realidade e do contexto analisados para serem utilizados, e, dessa forma, avaliar e julgar quando é apropriado ou não é primordial. Um exemplo é o uso do conceito de capital cultural que, para Bourdieu (1991, 2004a), pode ser representado, por exemplo, por visitas a museus, obras de arte. Isso, no entanto, não condiz com a realidade brasileira, uma vez que a cultura do país relacionada a obras de arte e museus é muito diferente da existente na França, país do sociólogo, no qual o conceito foi desenvolvido. Desse modo, as palavras de Wacquant e Akçaoğlu (2018, p. 152) são relevantes na afirmação de que "O Bourdieu turco não é o Bourdieu brasileiro, que não é o Bourdieu norueguês nem o Bourdieu francês". Por isso, por mais difícil que seja interpretar determinados conceitos, é possível entender que, ao serem utilizados, seja indispensável o autor expressar e transmitir o que determinado "conceito-chave" do seu trabalho significa.

Tudo o que aqui foi apresentado está alinhado com o que Bourdieu $(1989$, p. 45) frisou, na obra O Poder Simbólico, a respeito de que o problema é que apenas "reproduzimos a doxa recebida dos antepassados", sendo imprescindível uma ruptura por intermédio da conversão do olhar, de um novo olhar, de 'produzir' um novo homem, sendo necessária uma revolução mental, que envolva a mudança de toda a visão de mundo social. Para tanto, se não for pela quebra de paradigmas, como vamos produzir esse novo homem e novo olhar?

\section{AGRADECIMENTOS}

Conforme Portaria № 206, de 4 de setembro de 2018, o presente trabalho foi realizado com apoio da Coordenação de Aperfeiçoamento de Pessoal de Nível Superior - Brasil (CAPES) - Código de Financiamento 001. 


\section{REFERÊNCIAS}

Aranha, C. E., Rossoni, L., \& Mendes-da-Silva, W. (2016). Capital social do Conselho de administração e desempenho de empresas de capital aberto brasileiras. Revista de Administração Mackenzie, 17(1), 15-39.

Araújo, U. P., Brito, M. J., Ribeiro, L. M. P., \& Lopes, F. T. (2016). Meta interpretação: quinze anos de pesquisa com o Relatório da Administração. Revista Contabilidade \& Finanças, 27(71), 217-231.

Barbosa, J. E., Neto., Higgins, S. S. S., Cunha, J. V. A., \& Ribeiro, A. C. (2016). Capital social e seletividade em redes de coautoria acadêmica: o caso das ciências contábeis no Brasil. Brazilian Business Review, 13(6), 239-269.

Baxter, J., \& Chua, W. F. (2008). Be(com)ing the chief financial officer of an organization: Experimenting with Bourdieu's practice theory. Management Accounting Research, 19(3), 212-230.

Bourdieu, P. (1980). Le capital social: notes provisoires. Actes de la Recherche en Sciences Sociales, 31(31), 2-3.

Bourdieu, P. (1986). The forms of capital. In: J. G. Richardson (Ed.), Handbook of theory and research for the sociology of education (pp. 111-113). Westport, CO: Greenwood Press.

Bourdieu, P. (1989). O poder simbólico (4a ed.). Rio de Janeiro, RJ: Bertrand Brasil.

Bourdieu, P. (1991). Language and Symbolic Power. Cambridge, MA: Harvard University Press.

Bourdieu, P. (1992). O poder simbólico. Rio de Janeiro, RJ: Bertrand Brasil.

Bourdieu, P. (1997a). A dominação. Mont-Saint-Aignan, France: Universidade de Rouen.

Bourdieu, P. (1997b). Passport to duke. Metaphilosophy, 28(4), 449-455.

Bourdieu, P. (1998). O capital social - notas provisórias. In M. A. Nogueira, \& A. Catani (Eds.), Escritos de educação (pp. 65-70). Petrópolis, RJ: Vozes.

Bourdieu, P. (2000). Les structures sociales de l'économie. Paris, France: Éditions du Seuil.

Bourdieu, P. (2001). Meditações pascalianas. Rio de Janeiro, RJ: Bertrand Brasil.

Bourdieu, P. (2004a). Coisas Ditas. São Paulo, SP: Brasiliense.

Bourdieu, P. (2004b). Os usos sociais da ciência: por uma sociologia clínica do campocientífico. São Paulo, SP: Unesp.

Bourdieu, P. (2005). The social structures of the economy. Cambridge, UK: Polity Press.

Bourdieu, P., Chamboredon, J. C., \& Passeron, J. C. (2015). Ofício de sociólogo: metodologia da pesquisa na sociologia (8a ed.). Petrópolis, RJ: Vozes, 2015

Bourdieu, P., \& Wacquant, L. J. D. (1992). An invitation to reflexive sociology. Chicago, IL: University of Chicago Press.

Bryer, A. R. (2011). Accounting as learnt social practice: The case of the empresas recuperadas in Argentina. Accounting, Organizations and Society, 36(8), 478-493.
Burt, R. S. (1992). The social structure of competition. In N. Nohria, \& R. G. Eccles (Eds.), Networks and organizations: structure, form, and action (pp. 401-411). Boston, MA: Harvard Business School Press.

Burt, R. S. (2000). The new structure of social capital. Research in Organizational Behavior, 22, 345-423.

Coleman, J. S. (1988). Social capital in the creation of human capital. American Journal of Sociology, 94, 95-120.

Coleman, J. S. (1994). Foundations of social theory. Cambridge, MA: Harvard University Press.

Coleman, J. S. (1992). The rational reconstruction of society. Presidential Address. American Sociological Review, 58, 1-15.

Cooper, D. J., \& Hopper, T. (2006). Critical theorising in management accounting research. Handbooks of Management Accounting Research, 1, 207-245.

Dimaggio, P. J., \& Powell, W. W. (1991). The new institutionalism in organizational analysis. Chicago, IL: University of Chicago.

Dimaggio, P. J., \& Powell, W. W. (2004). The iron cage revisited. In: F. Dobbin (Ed.), The new economic sociology (pp. 111-134). Princeton, NJ: Princeton University.

Donadone, J. C. (2010). Consultoria internacional em expansão e formas emergentes de globalização das trocas e contenciosos gerenciais. Tempo social, 22(1), 101-125.

Farjaudon, A. L., \& Morales, J. (2013). In search of consensus: The role of accounting in the definition and reproduction of dominant interests. Critical Perspectives on Accounting, 24(2), 154-171.

Frezatti, F., Nascimento, A. R., \& Junqueira, E. (2009). Desenvolvimento da pesquisa em Contabilidade Gerencial: as restrições da abordagem monoparadigmática de Zimmerman. Revista Contabilidade \& Finanças, 20(49), 6-24.

Hey, A. P. (2017). Dominação. In A. M. Catani, M. A. Nogueira, A. P. Hey, \& C. Medeiros (Orgs.), Vocabulário Bourdieu. Belo Horizonte, MG: Autêntica Editora.

Homero, P. F., Jr. (2017). A constituição do campo científico e a baixa diversidade da pesquisa contábil brasileira. Revista de Educação e Pesquisa em Contabilidade, 11(3), 314-328.

Hoskin, K. W., \& Macve, R. H. (1986). Accounting and the examination: a genealogy of disciplinary power. Accounting, Organizations and Society, 11(2), 105-136.

Kuruppu, C., Adhikari, P., Gunarathna, V., Ambalangodage, D., Perera, P., \& Karunarathna, C. (2016, December). Participatory budgeting in a Sri Lankan urban council: A practice of power and domination. Critical Perspectives on Accounting, 41, 1-17.

Lahire, B. (2017). Campo. In A. M. Catani, M. A. Nogueira, A. P. Hey, \& C. Medeiros (Orgs.), Vocabulário Bourdieu (pp. 64-66). Belo Horizonte, MG: Autêntica Editora.

Lebaron, F. (2017). Capital. In A. M. Catani, M. A. Nogueira, A. P. Hey, \& C. Medeiros (Orgs.), Vocabulário Bourdieu (pp. 101-102). Belo Horizonte, MG: Autêntica Editora. 
Lin, N., Cook, K. S., \& Burt, R. S. (2001). Social capital: Theory and research. New Jersey, NJ: Transaction Publishers.

Machado-da-Silva, C. L., Guarido, E. R., Filho, \& Rossoni, L. (2010). Campos organizacionais: seis diferentes leituras e a perspectiva de estruturação. RAC-Revista de Administração Contemporânea, 14(esp.), 109-147.

Malsch, B., Gendron, Y., \& Grazzini, F. (2011). Investigating interdisciplinary translations: The influence of Pierre Bourdieu on accounting literature. Accounting, Auditing \& Accountability Journal, 24(2), 194-228.

Mauger, G. (2017). Violência Simbólica. In A. M. Catani, M. A. Nogueira, A. P. Hey, \& C. Medeiros (Orgs.), Vocabulário Bourdieu (pp. 359-361). Belo Horizonte, MG: Autêntica Editora.

Meneghetti, F. K. (2011). O que é um ensaio-teórico? Revista de Administração Contemporânea, 15(2), 320-332.

Miranda, G. J., Casa Nova, S. P. C., \& Cornacchione, E. B., Jr. (2012). Os saberes dos professores-referência no ensino de contabilidade. Revista Contabilidade \& Finanças, 23(59), 142-153.

Mizumoto, F. M., Artes, R., Lazzarini, S. G., Hashimoto, M., \& Bedê, M. A. (2010). A sobrevivência de empresas nascentes no estado de São Paulo: um estudo sobre capital humano, capital social e práticas gerenciais. Revista de Administração, 45(4), 343-355.

Munro, R. (1993). Just when you thought it safe to enter the water: Accountability, language games and multiple control technologies. Accounting, Management and Information Technologies, 3(4), 249-271.
Nogueira, M. A. (2017). Capital cultural. In A. M. Catani, M. A. Nogueira, A. P. Hey, \& C. Medeiros (Orgs.), Vocabulário Bourdieu (pp. 103-106). Belo Horizonte, MG: Autêntica Editora.

Riccio, E. L., Mendonça, O. R., Neto, \& Sakata, M. C. G. (2007). Movimentos de teorias em campos interdisciplinares: a inserção de Michel Foucault na contabilidade. Revista de Administração Contemporânea, 11(2), 11-32.

Setton, M. G. J. (2002). A teoria do habitus em Pierre Bourdieu: uma leitura contemporânea. Revista Brasileira de Educação, 20, 60-70.

Tana, W., Mesquita, J. M. C., Gonçalves, C. A., \& Martins, H. C. (2017). Redes Sociais, Capital social e Desempenho: Estudo com Cooperativas Brasileiras do Segmento Lácteo. Revista de Ciências da Administração, 19(48), 38-53.

Townley, B. (2014). Bourdieu and Organizational Theory: A Ghostly Aparition? In P. Adler, P. Du Gay, G. Morgan, \& M. Reed (Eds.), The Oxford Handbook of Sociology, Social Theory, and Organization Studies: Contemporary Currents (pp. 39-63). Oxford, UK: Oxford University Press.

Valle, I. R. (2008). Pierre Bourdieu: A pesquisa e o pesquisador. In L. Bianchetti, \& P. Meksenas (Org.), A trama do conhecimento. Teoria, método e escrita em ciência e pesquisa (pp. 95-117). Campinas, SP: Papirus.

Wacquant, L., \& Akçaoglu, A. (2018). Prática e poder simbólico em Bourdieu: a visão de Berkeley. BIB, 85(1), 148-163.

Whittle, A., \& Mueller, F. (2010). Strategy, enrolment and accounting: the politics of strategic ideas. Accounting, Auditing \& Accountability Journal, 23(5), 626-646.

Mara Vogt

ORCID: https://orcid.org/0000-0002-3951-4637

Doutora em Ciências Contábeis e Administração pela Universidade Regional de Blumenau (FURB); Professora dos cursos de Graduação de Ciências Contábeis e Administração da Universidade Federal de Santa Catarina (UFSC). E-mail: maravogtcco@gmail.com

Marcia Zanievicz da Silva

ORCID: https://orcid.org/0000-0003-1229-7705

Doutora em Ciências Contábeis e Administração pelo Programa de Pós-Graduação em Ciências Contábeis da Universidade Regional de Blumenau (PPGCC/FURB); Professora do Programa de Pós-Graduação em Ciências Contábeis e Administração da Universidade Regional de Blumenau (FURB). E-mail:marciaza@gmail.com 